\title{
Computer simulation of pressure welding of heat resistant heterophase nickel-based superalloys specimens through an interlayer
}

\author{
A. Kh. Akhunova ${ }^{\dagger}$, V. A. Valitov, E. V. Galieva \\ †akhunova.a.a@gmail.com \\ Institute for Metals Superplasticity Problems, RAS, Ufa, 450001, Russia
}

\begin{abstract}
Computer simulation of pressure welding of cylindrical workpieces through an interlayer was carried out using the DEFORM-2D software package in a two-dimensional formulation (axisymmetric deformation). Two combinations of materials to weld were considered: sample I - cylinders of heterophase nickel-based deformable superalloy EP975 in a coarsegrained state were welded through an interlayer of EP975 with a fine-grained microduplex structure; sample II — cylinders of dissimilar nickel-based alloys, one the deformable alloy EP975 in a coarse-grained state and the other an intermetallic alloy VKNA-25 with a single-crystal structure, were welded through an interlayer of EP975 alloy with a fine-grained microduplex structure. The welding process was carried out under isothermal conditions at a temperature of $1125^{\circ} \mathrm{C}$ and an initial strain rate of $10^{-4} \mathrm{~s}^{-1}$. The material characteristics were described by experimental curves obtained under uniaxial compression tests of alloys at the welding temperature. The Siebel friction model was used to describe the contact conditions on the surfaces to be welded. The friction coefficient was taken equal to 0.3. The distribution of equivalent, axial, radial, circumferential and shear components of stress and strain in the samples have been investigated. Analysis of the simulation results allowed one to conclude that, in comparison to welding of similar materials, during welding of dissimilar materials the values of the radial, axial and circumferential stresses increase. Radial and circumferential stresses in the material of the cylinders are tensile, while compressive stresses prevail in the material of the interlayer. Area with the maximum values of shear stresses in the region of contact between the cylinders and the interlayer also increases. In this case, axial, radial and circumferential strains decrease in a cylinder made from a material with higher strength, the overall level of shear strain does not change, and on the reciprocal contact surface of the interlayer, the region of extension of maximum shear strain extends to the entire contact zone. Such a combination of factors allows one to conclude on more favorable pressure welding conditions for welding of dissimilar alloys in comparison with similar materials.
\end{abstract}

Keywords: finite-element modeling, pressure welding, superplasticity, nickel-based superalloy.

УДК: 621.791 .18

\section{Компьютерное моделирование сварки давлением образцов из гетерофазных никелевых сплавов через прослойку}

\author{
Ахунова А. Х. ${ }^{\dagger}$ Валитов В. А., Галиева Э. В. \\ Институт проблем сверхпластичности металлов РАН, Уфа, 450001, Россия
}

Проведено компьютерное моделирование процесса сварки давлением цилиндрических заготовок через прослойку с помощью программного комплекса DEFORM-2D в двумерной постановке (осесимметричная деформация). Рассматривались два сочетания свариваемых материалов: образец I - цилиндры из гетерофазного никелевого деформируемого сплава ЭП975 в крупнозернистом состоянии сваривались через прослойку из ЭП975 с мелкозернистой микроструктурой типа микродуплекс; образец II - цилиндры из разноименных никелевых сплавов, деформируемого сплава ЭП975 в крупнозернистом состоянии и интерметаллидного сплава ВКНА-25 с 
монокристаллической структурой, сваривались через прослойку из сплава ЭП975 с мелкозернистой микроструктурой. Сварка проводилась в изотермических условиях при температуре $1125^{\circ} \mathrm{C}$ и начальной скорости деформации $10^{-4} \mathrm{c}^{-1}$. Материал задавался экспериментальными кривыми, полученными при одноосном сжатии исследуемых сплавов в выбранных структурных состояниях при температуре сварки. Контактные условия на свариваемых поверхностях описывались моделью трения по Зибелю. Величина коэффициента трения принималась равной 0.3 . Исследовано распределение эквивалентных, осевых, радиальных и окружных компонент напряжений и деформаций в образцах. Анализ результатов моделирования позволяет сделать вывод, что по сравнению со сваркой одноименных материалов, при сварке разноименных материалов увеличиваются значения радиальных, осевых и окружных напряжений. Радиальные и окружные напряжения в материале цилиндров являются растягивающими, а в материале прослойки преобладают сжимающие. Также увеличивается область максимальных значений сдвиговых напряжений в области контакта цилиндров и прослойки. При этом в цилиндре из материала с бо́льшей прочностью уменьшаются осевые, радиальные и окружные деформации, общий уровень сдвиговых деформаций не меняется, а на ответной контактной поверхности прослойки область протяжения максимальных сдвиговых деформаций распространяется на всю контактную зону. Такое сочетание факторов позволяет сделать вывод о более благоприятных условиях при сварке давлением разноименных сплавов, чем при сварке одноимённых материалов.

Ключевые слова: конечно-элементное моделирование, сварка давлением, сверхпластичность, никелевый сплав.

\section{1. Введение}

Сварка давлением (СД), в том числе в условиях сверхпластичности (СП) [1-3], нашла широкое применение при изготовлении различных узлов и деталей конструкций во многих отраслях промышленности, а также в авиадвигателестроении [1-3,10-18]. Основными стадиями СД является образование контакта, т.е. сближение соединяемых заготовок за счет пластической деформации микронеровностей на свариваемых поверхностях, и активация контактных поверхностей [4-6]. Качество твердофазного соединения (ТФС) зависит от многих факторов: приложенного давления, температуры сварки, скорости нагружения, схемы деформирования $[4-8,17,19]$, рельефа свариваемых поверхностей [3,13-14], геометрии соединяемых деталей $[13,14]$, исходной микроструктуры заготовок $[10,11,15]$ и напряженно-деформированного состояния (НДС) в зоне ТФС свариваемых материалов $[3,15,17]$.

Подготовленная для образования физического контакта между заготовками структура должна быть однородной и мелкозернистой, чтобы обеспечить деформацию микронеровностей на контактных поверхностях заготовок в режиме СП $[10,11,15]$. Процесс получения мелкозернистой структуры в объемных заготовках из труднодеформируемых никелевых сплавов связан со значительной трудоемкостью и энергоемкостью. Поэтому при СД массивных объемных заготовок перспективным является использование тонких прослоек с мелкозернистой или ультрамелкозернистой структурой микроструктурой.

Узлы двигателей газотурбинных двигателей (ГТД) из жаропрочных никелевых сплавов нередко изготавливаются из разнородных материалов, имеющих различные модули упругости и жаропрочные характеристики. Вследствие этого в зоне соединения сложно обеспечить одинаковые условия деформирования на обеих заготовках, что ведет к перераспределению напряженно-деформированного состояния, и может существенно влиять на качество сварного соединения.
Как известно $[4,6]$ при диффузионной сварке пластическая деформация свариваемых деталей не превышает 5\%. В то же время при СД в условиях СП степень деформации может составлять 20-40\%. В этой связи, изучение НДС заготовок при сварке давлением является актуальной задачей.

В данной работе с помощью компьютерного моделирования проведено исследование НДС цилиндрических образцов из сплавов на основе никеля, полученных СД в условиях СП с использованием прослойки из мелкозернистого материала. Для оценки возможности получения качественного соединения был рассмотрен характер распределения различных компонент деформации и напряжений - эквивалентные, осевые, радиальные, окружные и сдвиговые. В качестве материалов для свариваемых образцов были выбраны высоколегированные никелевые сплавы: ЭП975 в крупнозернистом состоянии и интерметаллидный сплав ВКНА-25 с монокристаллической структурой. Для материала прослойки был выбран ЭП975 с мелкозернистой микроструктурой типа микродуплекс.

\section{2. Методика компьютерного моделирования}

Компьютерное моделирование сварки давлением цилиндрических образцов через прослойку проводили в двумерной постановке (осесимметричная деформация) с помощью программного комплекса DEFORM-2D. Рассматривались два типа составных образцов:

Образец I - цилиндры из деформируемого сплава ЭП975 в крупнозернистом состоянии (ЭП975-КЗ) сваривались через прослойку из ЭП975 с мелкозернистой микроструктурой (ЭП975-МЗ). Диаметр образцов составлял 15.6 мм, высота цилиндров и прослойки была равна 20 и 1.6 мм, соответственно;

Образец II - цилиндры из разноименных сплавов на основе никеля, деформируемого сплава ЭП975-КЗ и интерметаллидного сплава ВКНА-25 с монокристаллической структурой (ВКНА-25), сваривались также 


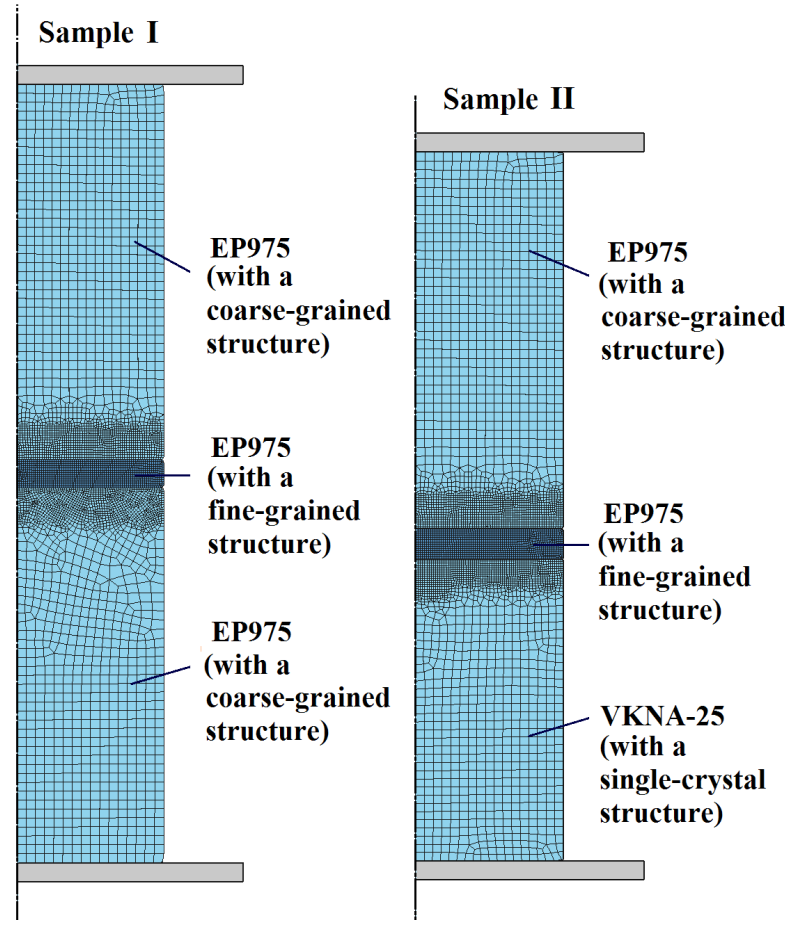

Рис. 1. Конечно-элементная модель образцов I и II.

Fig. 1. Finite element model of samples I and II.

через прослойку из сплава ЭП975-МЗ. Диаметр образцов составлял 15.6 мм, высота цилиндров из сплавов ЭП975-КЗ и ВКНА-25 принималась равной 20 и 16 мм, соответственно. Высота прослойки принималась равной $1.6 \mathrm{Mм}$.

Компьютерная модель образцов I и II представлена на Рис. 1. При расчете рассматривалась половина всех образцов с учетом плоскости симметрии на левой границе расчетного блока. Более тонкое разбиение сетки на элементы задавалось в зоне контактного взаимодействия заготовок. Количество элементов в цилиндре - 1700, в прослойке - 1000. Деформирующие инструменты (траверсы) принимались абсолютно жесткими, деформируемые тела имели свойства упругопластичных. Контактные условия на свариваемых поверхностях описывались моделью трения по Зибелю. Величина коэффициента трения принималась равной 0.3 .

Сварка проводилась в изотермических условиях при температуре $1125^{\circ} \mathrm{C}$ и начальной скорости деформации $10^{-4} \mathrm{c}^{-1}$. Характеристики изучаемых материалов задавались экспериментальными кривыми, полученными при одноосном сжатии сплавов при температуре сварки. Отметим, что материал прослойки ЭП975-М3 (модуль упругости $E=130$ ГПа, предел текучести $\sigma_{T}=45 \mathrm{MПа)} \mathrm{имеет} \mathrm{меньшую} \mathrm{жесткость} \mathrm{и} \mathrm{прочность,}$ чем материал ЭП975-К3 (модуль упругости $E=140$ ГПа, предел текучести $\sigma_{T}=100 \mathrm{MПа),} \mathrm{и} \mathrm{бо́льшую} \mathrm{жесткость}$ и меньшую прочность, чем ВКНА-25 (модуль упругости $E=90$ ГПа, предел текучести $\sigma_{T}=300 \mathrm{MПа).} \mathrm{В} \mathrm{качестве}$ примера на Рис. S1 (дополнительный материал) приведены кривые «напряжение-деформация» для скорости деформации $10^{-4} \mathrm{c}^{-1}$.

\section{3. Результаты моделирования}

При сварке давлением образцы подвергали сжатию до степени деформации верхнего цилиндра $\approx 2.5 \%$. Результаты моделирования показали, что при СД Образца I, оба цилиндра из сплава ЭП975-КЗ деформируются на одну величину степени деформации (2.5\%), которая в 5.2 раза меньше, чем у прослойки из сплава ЭП975-М3 (13\%). При СД Образца II цилиндр из ВКНА-25 практически не деформируется (0.2\%) в отличие от менее прочного цилиндра из ЭП975-КЗ (2.5\%). Степень деформации прослойки была равна $13 \%$. Эпюры распределения эквивалентных напряжений и деформаций приведены на Рис. S2 (дополнительный материал). Известно [1-3,12], что СД в условиях СП при высоких температурах и низких скоростях деформации позволяет исключить возникновение значительных термических и фазовых напряжений в зоне ТФС, которые крайне нежелательны при соединении высоколегированных жаропрочных сплавов на основе никеля, а также интерметаллидных никелевых сплавов типа ВКНА-25.

На Рис. 2 и 3 представлены результаты моделирования в виде эпюр распределения компонент напряжений для Образцов I и II, соответственно. Отметим, что эквивалентные и сдвиговые напряжения обеспечивают физический контакт соединяемых поверхностей за счет пластической деформации материалов и активацию процессов взаимодействия этих поверхностей, а осевые напряжения характеризуют степень сближения соединяемых поверхностей.

Анализ картин распределения радиальных компонент напряжений (Рис. 2 a и 3 a) показал, что в зоне сварки на контакных поверхностях образцов наблюдаются $\sigma_{R}$ со знаком «+», т.е. растягивающие напряжения. В прослойке в центральной части преобладают $\sigma_{R}$ со знаком «-», т.е. сжимающие напряжения, величина которых по мере продвижения к периферии сварного соединения монотонно уменьшается до нуля. Материал прослойки мягче, чем материал образцов, и он начинает постепенно выдавливаться из зоны соединения от центра к периферии, что вызывает перераспредление напряжений в материале. Такая картина наблюдается для обоих образцов. При этом общий уровень $\sigma_{R}$ в Образце II выше в три раза, чем в Образце I.

Максимальные растягивающие окружные напряжения $\sigma_{\theta}$ в цилиндрах сосредоточены вблизи сварного соединения $\approx 3$ МПа (Образец I) и $7.5 \mathrm{MПа} \mathrm{(Образец} \mathrm{II)}$ (Рис. $2 \mathrm{~b}$ и $3 \mathrm{~b}$ ). Распределение $\sigma_{\theta}$ в прослойке неравномерное - от центра образца к его периферии они меняются со сжимающих на растягивающие: с -13 до 3 МПа для Образца I, и с -30 до 7 МПа для Образца II.

Осевые напряжения $\sigma_{z}$ (Рис. 2 с и 3 c) в цилиндрах и прослойке распределены равномерно и однородно для обоих образцов. Общий уровень $\sigma_{z}$ для Образца II выше примерно в 2 раза, чем для Образца I.

Сдвиговые напряжения $\sigma_{R Z}$ (Рис. $2 \mathrm{~d}$ и $3 \mathrm{~d}$ ) увеличиваются на границе контакта прослойки и цилиндров, при этом они максимальны на периферии сварного соединения, уменьшаясь по мере продвижения к центру. 


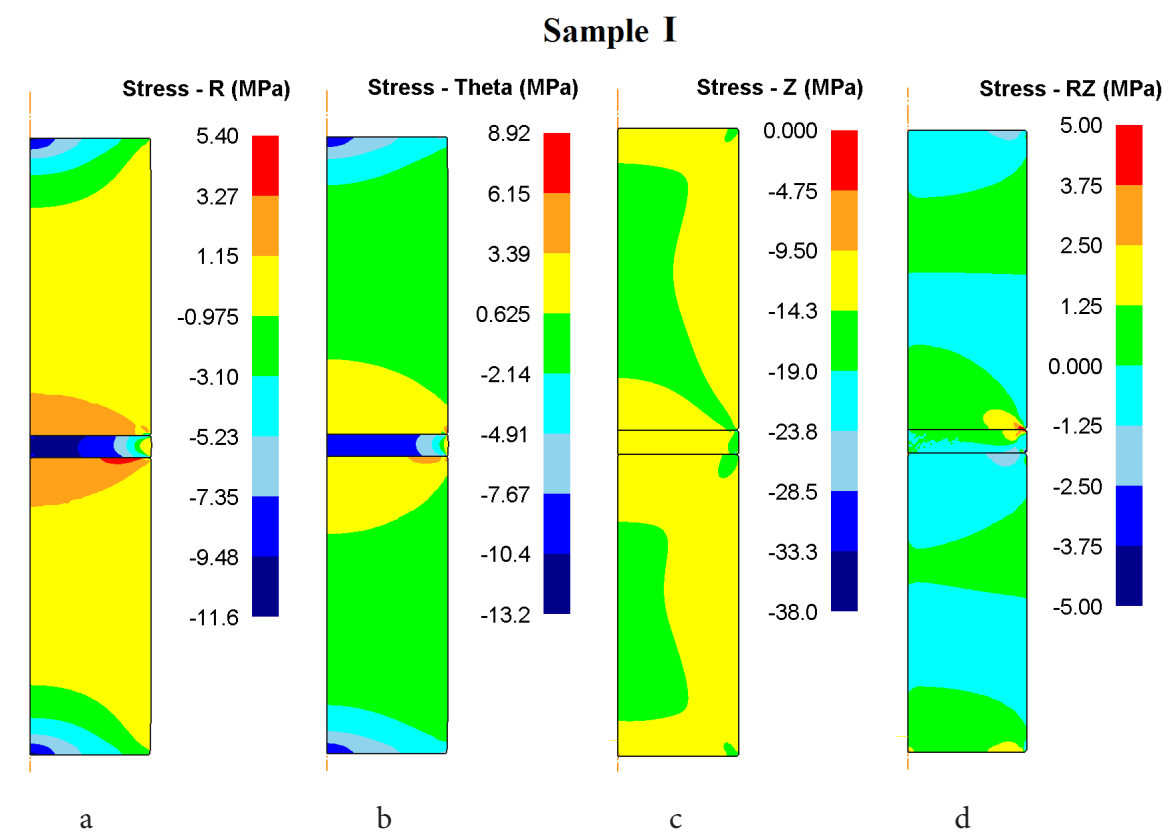

Pис. 2. (Color online) Распределение радиальных (a), окружных (b), осевых (c) и сдвиговых (d) напряжений в Образце I.

Fig. 2. (Color online) The distribution of radial (a), axial (b), circumferential (c) and shear (d) stresses during pressure welding of Sample I.

Sample II

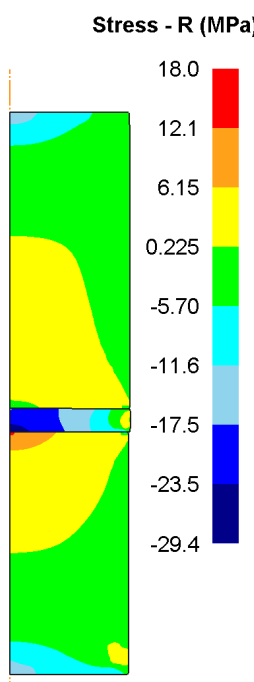

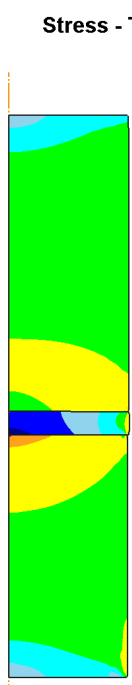

$\mathrm{b}$

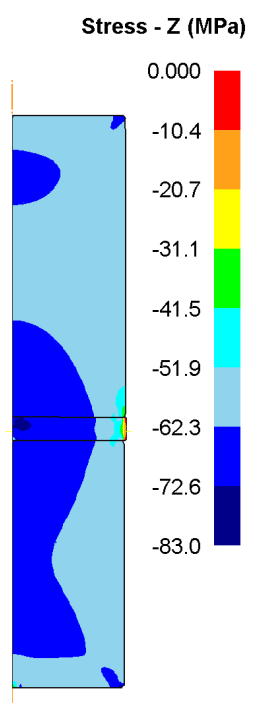

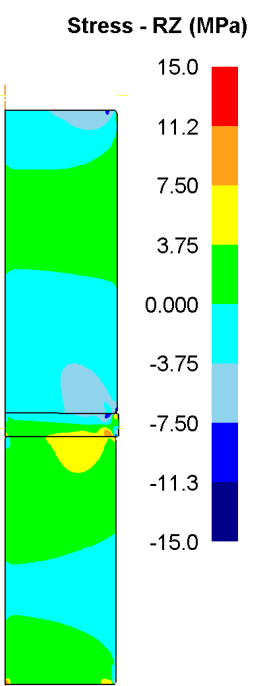

d

Pис. 3. (Color online) Распределение радиальных (a), окружных (b), осевых (c) и сдвиговых (d) напряжений в Образце II.

Fig. 3. (Color online) The distribution of radial (a), axial (b), circumferential (c) and shear (d) stresses during pressure welding of Sample II.

При сварке Образца II область максимальных сдвиговых напряжений на контактной поверхности цилиндра из ВКНА-25 больше, чем на контактной поверхности цилиндра из ЭП975-КЗ, при этом она распространяется практически на всю контакную область с прослойкой.

Таким образом, можно сделать вывод, что при сварке Образца II, по сравнению с Образцом I, увеличиваются значения радиальных, осевых и окружных напряжений. При этом радиальные и окружные напряжения в материале цилиндров являются растягивающими, а в материале прослойки преобладают сжимающие. Также увеличивается область максимальных значений сдвиговых напряжений в области контакта цилиндров и прослойки. Такое сочетание факторов позволяет сделать вывод о более благоприятных условиях при сварке давлением для Образца II. Отметим, что при сварке Образца I, осевые напряжения в зоне сварки существенно превышают сдвиговые напряжения, что при достаточно малой толщине прослойки может привести к разрушению.

На Рис. 4 и 5 представлены результаты моделирования в виде эпюр распределения компонент деформаций для Образцов I и II, соответственно.

Анализ эпюр распределения компонент деформации для Образца I (Рис. 4) позволяет сделать вывод, что 


\section{Sample I}

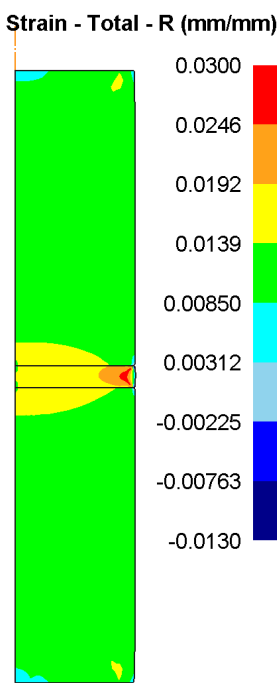

a

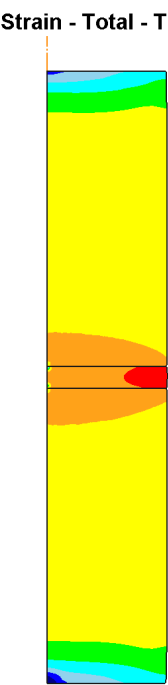

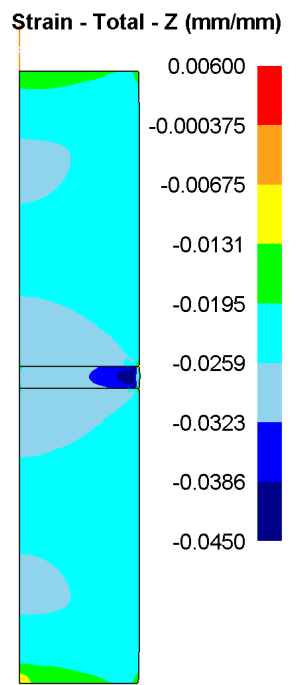

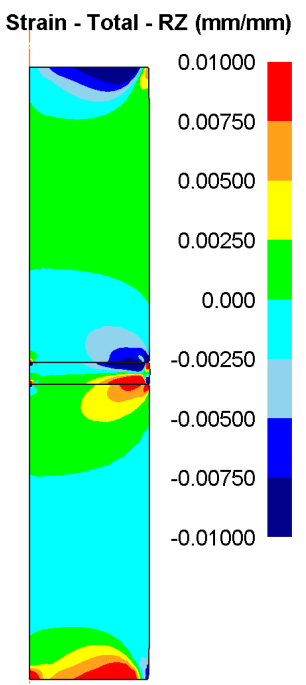

d

Pис. 4. (Color online) Распределение радиальных (a), окружных (b), осевых (c) и сдвиговых (d) деформаций в Образце I.

Fig. 4. (Color online) The distribution of radial (a), axial (b), circumferential (c) and shear (d) strain during pressure welding of Sample I.

\section{Sample II}

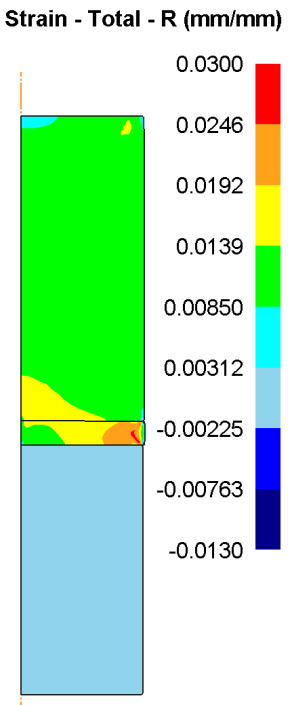

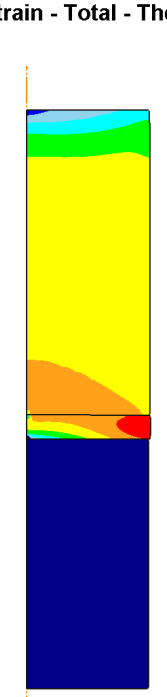

$\mathrm{b}$

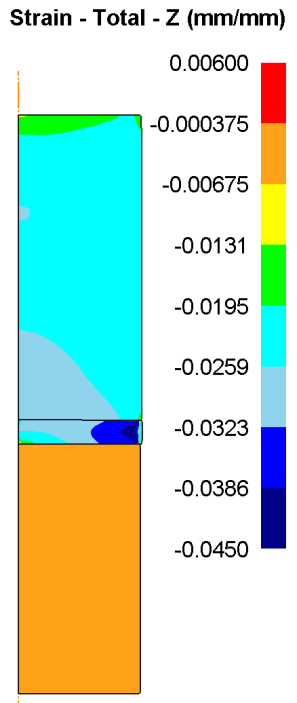

$\mathrm{C}$

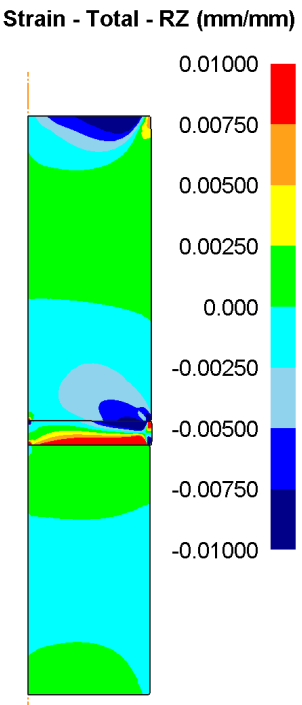

$\mathrm{d}$

Pис. 5. (Color online) Распределение радиальных (a), осевых (b), окружных (c) и сдвиговых деформаций (d) в Образце II.

Fig. 5. (Color online) The distribution of radial (a), axial (b), circumferential (c) and shear (d) strain during pressure welding of Sample II.

для всех них характерна локализация максимума значений вблизи контактных поверхностей цилиндров и прослойки. Радиальные деформации $\varepsilon_{R}$ (Рис. 4 a) по всей области образца являются растягивающими, достигая своего максимума в периферийной области прослойки - 0.03. Окружные деформации $\varepsilon_{\theta}$ (Рис. 4 b) также являются растягивающими и увеличиваются по мере продвижения от торца цилиндра к зоне сварного соедиения на порядок - от 0.004 до 0.02. Максимальное значение $\varepsilon_{\theta}$ достигается в периферийной области прослойки. Осевые деформации $\varepsilon_{z}$ (Рис. 4c) по всей области образца являются сжимающими, также лока- лизуя максимальное значение в периферийной области прослойки - 0.45. Сдвиговые деформации $\varepsilon_{R Z}$ (Рис. $4 \mathrm{~d}$ ), в соответствии с эпюрами распределения сдвиговых напряжений, увеличиваются на границе контакта прослойки и цилиндров, и также максимальны на периферии сварного соединения образца, уменьшаясь по мере продвижения к центру.

Характер распределения компонент деформации для Образца II (Рис. 5) меняется вследствие того, что материал нижнего цилиндра ВКНА-25 имеет меньшую жесткость и большую прочность, чем ЭП975-КЗ. Картины распределения компонент дефор- 
мации в верхнем цилиндре практически одинаков для обоих образцов. Однако вследствие того, что нижний цилиндр в Образце II из ВКНА-25 практически не деформируется, то значения компонент деформаций в нем очень малы, и все они распределены достаточно равномерно и однородно. Отличие также наблюдается в картинах распределения сдвиговых компонент деформации $\varepsilon_{R Z}$ (Рис. $5 \mathrm{~d}$ ). На контактной поверхности нижнего цилиндра (ВКНА-25) величина сдвиговых деформаций не имеет максимума на периферии образца, как наблюдается в Образце I. На ответной контактной поверхности прослойки область максимальных сдвиговых деформаций распространяется практически на всю контакную область.

Таким образом, в прослойке деформации увеличиваются от центра образца к его периферии, при этом деформации в прослойке Образца II распределены более неравномерно, чем в Образце I.

При сварке Образца II в нижнем цилиндре из ВКНА-25 уменьшаются осевые, радиальные и окружные деформации, по сравнению с нижним цилиндром из ЭП975 в Образце I, однако общий уровень сдвиговых деформаций не меняется, а на ответной контактной поверхности прослойки область протяжения максимальных сдвиговых деформаций распространяется на всю контакную зону. Следовательно, уровень активации поверхности цилиндра такой же, как и в Образце I, при этом активация поверхности прослойки улучшается, что может благоприятно сказываться на качестве сварного соединения.

Данные компьютерного моделирования по сварке давлением жаропрочных никелевых сплавов через прослойку хорошо согласуются с результатами физических экспериментов. Проведенные испытания на растяжение плоских образцов при комнатной температуре, вырезанных из центральной части сваренных заготовок (Рис. S3, дополнительный материал), показало различие в их характере разрушения. По результатам эксперимента установлено, что образцы, полученные сваркой одноименных материалов, разрушаются по зоне ТФС, а образцы, полученные сваркой разноименных материалов, разрушаются по сплаву ВКНА-25 (Рис. S3, дополнительный материал).

\section{4. Выводы}

Анализ напряженно-деформированного состояния свариваемых Образцов I и II позволяет сделать следующие выводы:

1. При сварке цилиндров из разноименных никелевых сплавов ЭП975-КЗ и ВКНА-25 через прослойку из ЭП975-МЗ и в цилиндрах, и в прослойке увеличивается общий уровень значений эквивалентных и осевых сжимающих напряжений по сравнению со сваркой цилиндров из сплава ЭП975-КЗ, что благоприятно влияет на развитие физического контакта свариваемых поверхностей.

2. При сварке разноименных сплавов область максимальных сдвиговых напряжений, определяющих локализацию деформации, и отвечающих за активацию свариваемых поверхностей, увеличивается по сравнению со сваркой одноименных сплавов. При этом данная область распространяется практически на всю контакную поверхность прослойки и цилиндра из BКНА-25.

3. При сварке разноименных сплавов в нижнем цилиндре из материала с бо́льшей прочностью (ВКНА-25) уменьшаются осевые, радиальные и окружные деформации по сравнению с нижним цилиндром (ЭП975-КЗ) при сварке одноименных сплавов. При этом общий уровень сдвиговых деформаций, достигаемых в образцах, существенно не отличается, а на ответной контактной поверхности прослойки область протяжения максимальных сдвиговых деформаций распространяется на всю контакную зону, что может говорить об улучшении активации поверхности в зоне сварки.

Дополнительный материал/Supplementary material. Электронная версия статьи содержит дополнительньй материал, доступный безвозмездно на сайте журнала (lettersonmaterials.com). I The online version of this paper contains supplementary material available free of charge at the journal's Web site (lettersonmaterials.com).

Благодарности / Acknowledgements. Моделирование и экспериментальные данные для моделирования получены по госзаданию № АААA-A17-117041310215-4. / The computer modeling and a mechanical properties part was supported by the IMSP RAS State assignment No. AAAA-A17-117041310215-4.

\section{Литература/References}

1. Z. Heng, M. Maeda, Y. Takahashi. IOP Conference Series: Materials Science and Engineering. 61 (1), 012003 (2014). Crossref

2. R.R. Mulyukov et al. Lett. Mater. 8 (4s), 510 (2018). $\underline{\text { Crossref }}$

3. E. V. Galieva, R. YA. Lutfullin, A. Kh. Akhunova, V.A. Valitov, S.V. Dmitriev. Science and technology of welding and joining. 23 (7), 612 (2018). Crossref

4. E.S. Karakozov. Metal pressure welding. Moscow, Mashinostroenie (1986) 280 p. (in Russian) [Э.С. Каракозов. Сварка металлов давлением. Москва, Машиностроение (1986) 280 с.]

5. R.A. Musin, V.N. Antsiferov, V.F. Kvasnitsky. Diffusion welding of heat-resistant alloys. Moscow, Metallurgiya (1979) 208 p. (in Russian) [Р. А. Мусин, В. Н. Анциферов, В.Ф. Квасницкий. Диффузионнная сварка жаропрочных сплавов. Москва, Металлургия (1979) 208 с.]

6. A.V. Lyushinsky. Diffusion welding of dissimilar materials. Moscow, Academiya (2006) 208 p. (in Russian) [А.В. Люшинский. Диффузионная сварка разнородных материалов. Москва, Академия (2006) 208 c.]

7. A.S. Gelman. Basics of pressure welding. Moscow, Mashinostroenie (1970) 312 p. (in Russian) [А.С. Гельман Основы сварки давлением. Москва, Машиностроение (1970) 312 с.] 
8. A. V. Lyushinsky, E. V. Nikolic, A.A. Zhloba, S. V. Kharkovsky. Welding production. 5, 25 (2014). (in Russian) [A.В. Люшинский, Е.В. Николич, А.А. Жлоба, С.В. Харьковский. Сварочное производство. 5, 25 (2014).]

9. O.A. Kaibyshev, R.V. Safiullin, R. Ya. Lutfullin, V.V. Astanin. Journal of Materials Engineering and Performance. 8 (2), 205 (1999). Crossref

10. O.A. Kaibyshev, R. Ya. Lutfullin, V.K. Berdin. Acta Metallurgica et Materialia. 42 (8), 2609 (1994). Crossref

11. C. Soares. Gas Turbines. A Handbook of Air, Land and Sea Applications. Oxford, Butterworth-Heinemann, Elsevier (2015).

12. A. V. Logunov, Yu. N. Shmotin. Modern high-temperature nickel-based alloys for gas turbine. Moscow, Nauka i tekhnologiya (2013) 256 p. (in Russian) [А. В. Логунов, Ю.Н. Шмотин. Современные жаропрочные никелевые сплавы для дисков газовых турбин. Москва, Наука и технология (2013) 256 с.]

13. A. K. Akhunova, E. V. Valitova, S. V. Dmitriev, V. A. Valitov, R. Y. Lutfullin. Welding International. 30 (6), 488 (2016). Crossref
14. A.K. Akhunova, S.V. Dmitriev, V.A. Valitov, E.V. Galieva. Welding production. 12, 17 (2020). (in Russian) [А. Х. Ахунова, С. В. Дмитриев, В. А. Валитов, Э. В. Галиева. Сварочное производство. 12, 17 (2020).] 15. E. V. Valitova, R. Ya. Lutfullin, M. Kh. Mukhametrahimov, V. A. Valitov, A. Kh. Akhunova, S. V. Dmitriev. Lett. Mater. 4 (4), 291 (2014). Crossref

16. V. A. Valitov, A. K. Akhunova, E. V. Galieva, S. V. Dmitriev, R. Y. Lutfullin, M. Y. Zhigalova. Lett. Mater. 7 (2), 180 (2017). (in Russian) [В.А. Валитов, А.Х. Ахунова, Э.В. Галиева, С.В. Дмитриев, Р.Я. Лутфуллин, М.Ю. Жигалова. Письма о материалах. 7 (2), 180 (2017).] Crossref

17. A. K. Akhunova, et al. Lett. Mater. 6 (3), 211 (2016). (in Russian) [А.X. Ахунова и др. Письма о материалах. 6 (3), 211 (2016).] Crossref

18. A.K. Akhunova, V.A. Valitov, E. V. Galieva. Lett. Mater. 10 (3), 328 (2020). (in Russian) [А.Х. Ахунова, В. А. Валитов, Э. В. Галиева. Письма о материалах. 10 (3), 328 (2020).] Crossref

19. R. Ya. Lutfullin, et al. Advanced materials. 12, 295 (2011). (in Russian) [Р.Я. Лутфуллин и др. Перспективные материалы. 12, 295 (2011).] 